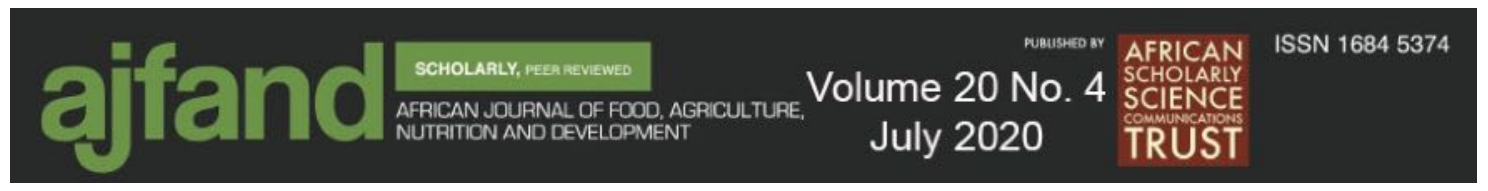

Afr. J. Food Agric. Nutr. Dev. 2020; 20(4): 16099-16111

https://doi.org/10.18697/ajfand.92.18690

\title{
POTENTIAL OF USING AMARANTHUS LEAVES TO FORTIFY INSTANT NOODLES IN THE SOUTH AFRICAN CONTEXT: A REVIEW
}

\section{Qumbisa ND ${ }^{1}$, Ngobese $\mathbf{N}^{2 *}$ and U Kolanisi ${ }^{1}$}

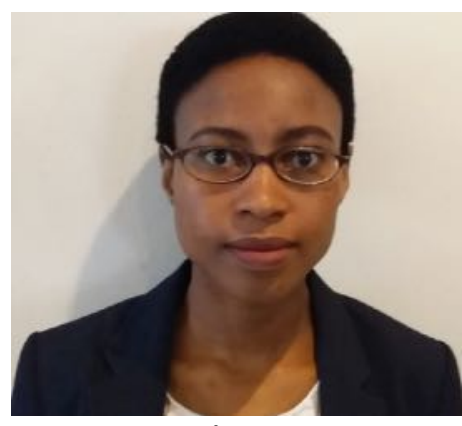

Nomali Ngobese
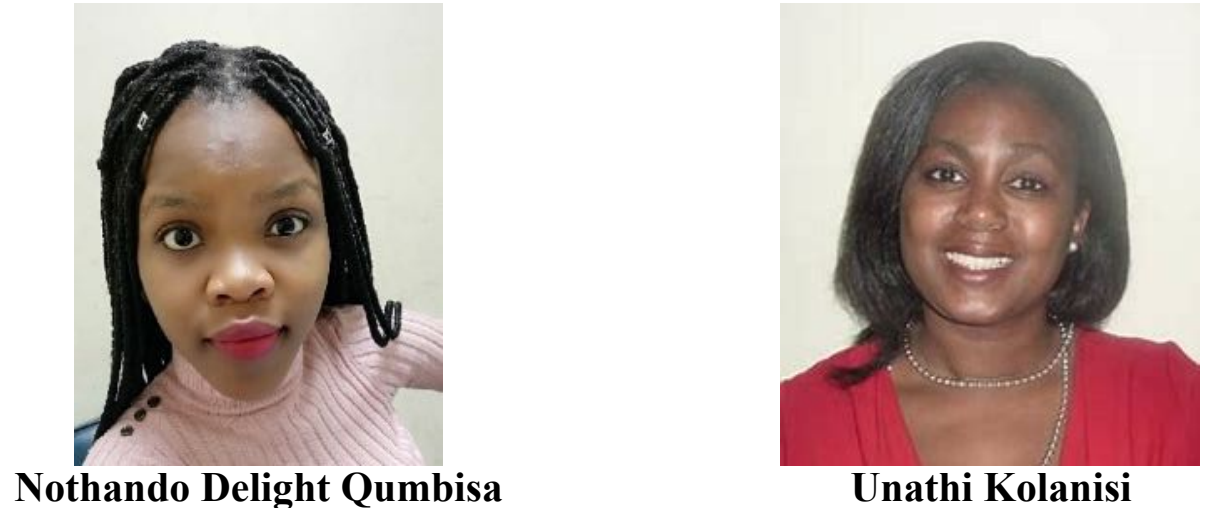

*Corresponding author email: ngobesen@uj.ac.za

${ }^{1}$ Department of Consumer Sciences, University of Zululand, P/Bag X1001, KwaDlangezwa, South Africa

${ }^{2}$ Department of Botany and Plant Biotechnology, University of Johannesburg, P.O. Box 524, Auckland Park, South Africa 


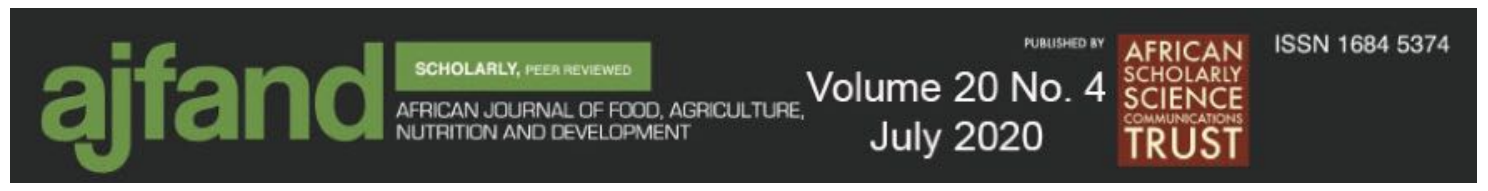

\begin{abstract}
There has been a significant increase in the consumption of instant noodles among the youth, especially students. According to literature, instant noodles are preferred because of their taste, extended shelf life, cheap price as well as convenience, which suit the busy lifestyle of the student population. However, it has been highlighted that instant noodles are not always a healthy food choice. The nutrient quality compromise poses a negative impact on the functioning of the body, which could affect the student's nutrition negatively. The objective of the study was, therefore, to determine the potential of Amaranthus leaf powder in fortifying instant noodles. Articles looking at instant noodle utilization and consumption by students as well as Amaranthus use, perceptions and utilization were used in this narrative review. These were selected and grouped by the authors according to the sub-topics mentioned above. Literature reports that instant noodles can be fortified by substituting wheat flour with Amaranthus grain flour. Studies on Amaranthus snacks and other starch-based foods using the leaf part have been reported but the fortification of noodles with Amaranthus leaf powder is not documented. The findings on the consumer acceptability of Amaranthus leaf powder-fortified foods have reported lower acceptability. This is due to unfamiliar sensory attributes such as a green color and a 'leafy' taste. Amaranthus is still perceived as food for poor and backward people, which contributes to lower acceptability of the plant to the youth. Nevertheless, Amaranthus leaves are considerably nutritious and the incorporation in staple foods could maximise crop utilization. Therefore, incorporation of Amaranthus with the noodles could lead to instant noodle indigenization in South Africa and give a sense of identity to the future generations. Furthermore, Amaranth-fortified noodles could sustain the utilization of traditional foods, promoting local-based food systems and help reduce unemployment among the youth.
\end{abstract}

Key words: instant noodles; consumer acceptability; morogo; fortification; imbuya, underutilized vegetables 


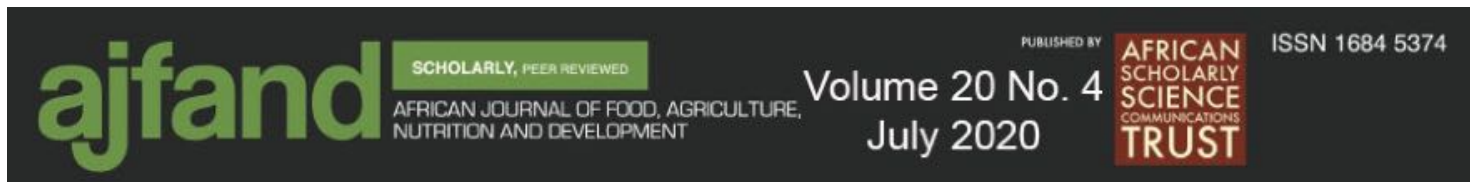

\section{INTRODUCTION}

It is estimated that the demand for instant noodles reached 103620 million servings per capita consumption globally in 2018 [1]. China leads the statistics at 40250 million servings whilst South Africa held the $25^{\text {th }}$ position with 260 million servings. For centuries, instant noodles were a staple food popular only in East Asian countries. However, their consumption has increasingly grown globally [2, 3]. Increasing consumption has been noted among the youth population, especially students $[4,5]$. According to literature, instant noodles are preferred because of their taste, extended shelf life, cheap price as well as convenience, which suit the busy lifestyle of the student population $[2,4,6]$. However, it has been highlighted that instant noodles are not always a healthy food choice [6]. There is a concern on the adequacy of nutrients obtained from instant noodles, especially when consumed as a single food item as a meal. This can lead to malnutrition if noodles are consumed in large portions and may be detrimental to the health of young women $[4,7,8]$. The nutrient quality compromise poses a negative impact on the functioning of the body, which can affect the students negatively [7]. As a result of the limited nutritional benefits of noodles, research focusing on flour fortification is on the rise and researchers are exploring the potential of fortifying noodles to make them a composite food to improve their nutritional value $[2,9]$.

Literature recommends that sensory quality, when fortifying instant noodles, should be of primary importance for consumer acceptability. Sensory attributes such as flavor, texture, color, the absence of a rancid taste after long-term storage as well as the cooking quality during meal preparation (for example, to be able to hydrate during cooking) have been noted [9]. Normally, wheat flour is used to produce instant noodles. However, this flour has low protein and dietary fiber contents, which can be supplemented through other ingredients. The protein can be of animal or plant origin; however, animal protein sources are costly as opposed to plant protein [3].

Amaranthus is an ancient plant that has been consumed in different regions and countries for over eight thousand years [10]. It is high in vitamins including $\beta$ carotene, vitamin B6, vitamin C, riboflavin, folate as well as selected amino acids [11]. Amaranthus grain and leaves are good sources of protein and minerals such as magnesium, calcium, potassium, phosphorus, iron and sodium [12]. This makes Amaranthus plant-based products a good source of various nutrients [10]. Amaranthus components are commonly used with wheat flour to produce nutrient-improved products, with grains being the most popular compared to leaves [13]. In southern Africa, Amaranthus leaves are often consumed as a steamed vegetable, with soups or as a relish $[10,14]$. Consequently, recent research has been focusing on this particular part of the plant. Consumer acceptability studies on Amaranthus and Amaranthus-based food products have been done with the youth and reported lower acceptability [11]. Nevertheless, the use of Amaranthus leaves is steadily gaining popularity in fortifying products that are low in nutrients [15]. In South Africa, the fortification of noodles with Amaranthus leaf powder has been tested by Nestlé [16]. However, nutritional composition and consumer acceptability evaluations have not been documented. 


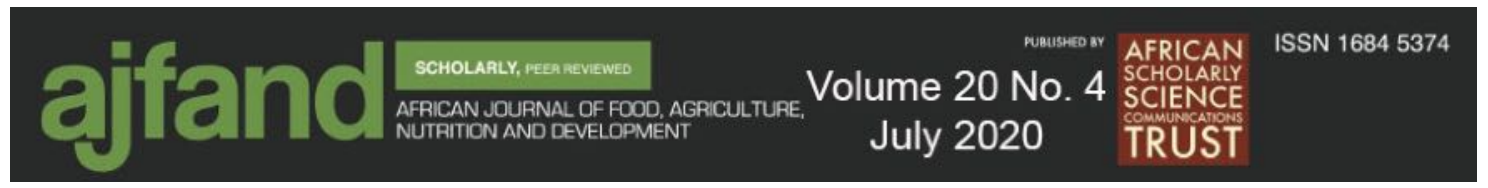

Therefore, this review looks at the potential of using Amaranthus leaf powder to fortify instant noodles to improve their nutritional value. The consumption of instant noodles in relation to the health concerns as well as the potential impact Amaranthus can have in improving instant noodle nutrients are considered. This is considered to be of importance as there are limited studies that report on the utilization of traditional African leafy vegetables, such as Amaranthus, as nutrient enhancers. This plant is underutilized due to consumer negative perceptions, especially among the youth.

\section{METHODS}

\section{Study design}

An online literature search was performed in May 2018 using the following databases: Google Scholar, Web of Science; Science Direct and Research Gate. The following key words were used: Amaranthus, imbuya, fast food consumption, instant noodle consumption, fortification, noodles, obesity, Amaranthus perceptions and benefits of Amaranthus. Articles published from 2009 to 2018 were selected for this review.

\section{Literature selection}

Seventy-five articles were obtained through the search engines and only 45 were included in this review. Selection was based on relevance to the title of the manuscript and the literature was used to structure the document according to the sub-topics below.

\section{Consumption of noodles and health concerns}

A survey reported by Huh et al. [8] outlined that most college students eat instant noodles many more times than adults who are non-students. Instant noodles are assumed to be one of the easiest, cheapest and satisfying convenience foods for students. They save students time to prepare and cook, as they relieve them of the task of gathering ingredients and cleaning up after food preparation [17]. The convenience attribute of the noodles makes them a preferred food for students [5, 18]. A concerning factor noted is that most often instant noodles were not eaten with vegetables or any protein items. This exposes students to malnutrition risks identified by the World Health Organization (WHO) [19]. Literature has shown that monotonous diets or reliance on starch-dense staple foods tends to result in hidden hunger and obesity [20].

More so, instant noodles have a high calorie content, refined carbohydrates, fats and sodium, with little or no vitamins and minerals contributing to an increased risk of metabolic diseases [8]. Reports also inform of young adults at the ages 20-49 in Korea who consume instant noodles the most to be vulnerable to death related to cardiovascular disease as well as cardiometabolic diseases due to the high salt, fat and glucose in instant noodles [8]. The high sodium concentration and fat content in noodles is a problem. Nine of the leading brands of the noodles were tested and were found to have an average of $1164 \mathrm{mg} / 100 \mathrm{~g}$ of sodium. South Africa introduced a new mandate to reduce salt content in foods, which became effective in 2016 [21]. The regulation's primary purpose is to reduce chronic diseases by addressing the $60 \%$ prevalence of salt associated with processed foods in the diet $[21,22]$. This regulation made it mandatory for food processing companies to reduce the salt content of foods, including instant noodles, which was to be reduced down to $800 \mathrm{mg}$ by 2019 [21, 22]. The use of different starches 


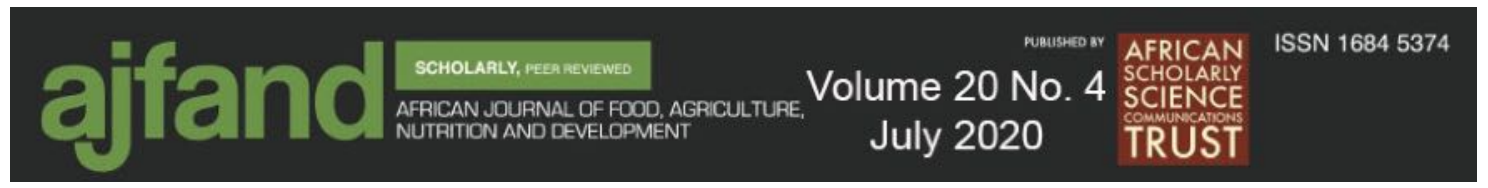

as bases for instant noodles also has different impacts on the health of people. Therefore, noodles should be consumed with vegetables and a source of proteins. As shown in Table 1 , each type of instant noodles is rich in certain nutrients. However, most fall short in one or more of the valuable nutrients. For example, the instant noodles made from rice, buckwheat, bean thread, and wheat flour are rich in carbohydrates, dietary fiber but low in fats. They offer little or no protein and potassium but have high amounts of sodium. This exposes the consumers of noodles to malnutrition-related diseases such as insulin resistance and hyperglycaemia [7], especially when they consume them as a single meal. A totally opposite scenario is realised in protein-rich-food instant noodles. For example, the egg and Ramen noodles offer twice the protein content as well as reduced salt levels. However, these offer little dietary fiber, no potassium as well as reduced levels of carbohydrates. This calls for a combination of ingredients in order to offer more nutrient dense noodles for the consumers. Amaranthus, being a source of a number of minerals including potassium, shows good potential to produce functional instant noodles.

Overconsumption of instant noodles has received attention recently due to its association with obesity and cardiometabolic syndrome among adults [18]. In a medical study done in 2014 in South Korea, Ramen instant noodles were reported to be a health risk among women as they lack protein, fiber, vitamins A, C \& B12, calcium, magnesium and potassium. Additionally, they lack antioxidants and phytochemicals, which affect health. The study suggested that if the Ramen instant noodles were consumed more than twice per week, that could lead to high blood sugar and cholesterol in women [23]. Ramen is a Japanese dish whose main ingredients include noodles and broth. It is usually served with meat and was initially introduced to reduce the workload of women in the country [24]. However, Ramen has been found to increase obesity, heart disease and diabetes. Hence, fortification strategies, which are less health compromising, should be investigated and introduced into the market for improved food and nutrition security.

\section{Instant noodle fortification}

Due to the concerns of micronutrient deficiencies, the World Health Organization (WHO) and the Food and Agriculture Organization (FAO) came up with strategies to reduce the prevalence of deficiencies. Among the proposed strategies were food fortification, supplementation, diet diversification and biofortification strategies. Fortification is a process whereby micronutrients are added to products that are identified to have a shortage [22]. Wheat flour fortification is among the programs with the aim of reducing the prevalence of anaemia [25]. Fortification is regarded as a sustainable strategy because it is cost-effective and does not require the target population to change its consumption patterns or diet as the process is done during the processing of foods that are already known. As an attempt to respond to the increased interests of healthier options for consumers, there is a growing trend in using different flour blends to produce healthier noodles from wheat flour $[8,26]$. The main goal of wheat flour blending is to improve the protein and fiber content of the noodles, hence cereals, vegetables, root crops and legumes rich in these nutrients have been widely used [2].

The pasta family, including instant noodles, has been identified to have foods that require protein and mineral fortification. These foods are generally rich in carbohydrates. However, the protein content and amino acid balance is not as high [27]. The 


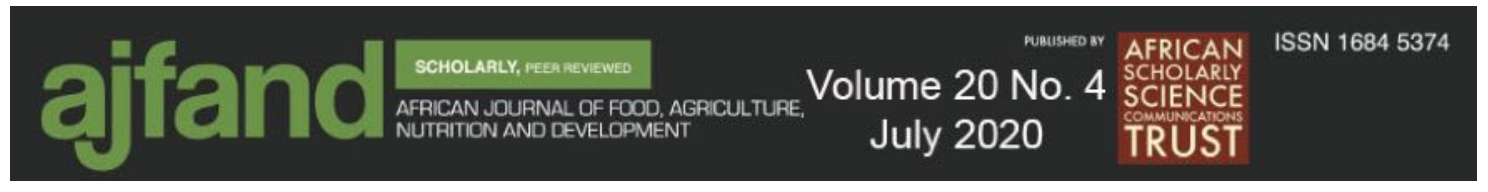

consumption of protein-enriched foods from plant sources has increased among healthconscious consumers and vegetarians [2]. Therefore, the use of plant protein has already penetrated the consumer markets, and, thus, the introduction of plant-based food fortification is not an unfamiliar concept. Blends using sweet potato flour, cassava flour, as well as cowpea and soybean flour are some examples that have been tried in noodle production. This blending helps improve the flavor, color and adds nutrients to instant noodles $[3,26]$. Instant noodles can be blended by fortifying the flour used to make the noodles or by fortifying the seasoning consumed with the noodles $[9,28]$. In a study conducted by Ganga et al. [29], it was shown that Moringa oleifera leaves can be used to improve the nutritional value of instant noodles; particularly the fiber content (by up to 4\%). Also, Shere et al. [30] and Ramu et al. [31] reported increased values for calcium (35.4-75.9 $\mathrm{mg}$ per $100 \mathrm{~g}$ ) and iron (2.7-4.8 mg per $100 \mathrm{~g}$ ) in spinach-fortified noodles. Reporting on the overall vitamin and mineral content of fortified noodles is uncommon as the focus has been on improving the protein and fiber contents. Sikander et al. [4], however, proposed that micronutrients such as vitamins A, B2 and B1, folic acid, niacin, and iron be improved by the fortification. Amaranthus being richer in these nutrients against spinach (commonly used) [32], leaves room for innovations around the vegetable.

\section{Amaranthus plant origin and nutritional value}

Amaranthus is one of the traditional African crops that originated from America $[10,37]$, which consists of about 60-70 species [12,33]. Grain Amaranthus species have been the most popular in various countries at various times over the years. Vegetable/leaves of Amaranthus have been used in China for over 400 years, yet they are more popular in the Caribbean and Africa. The Amaranthus species have adapted well in the sub-Saharan Africa region, where they grow in the wild in great quantities [11]. In South Africa, Amaranthus abundantly grows in the Limpopo, KwaZulu-Natal, North West and Mpumalanga provinces. It is commonly known as pigweed (English), Hanekam (Afrikaans), Thepe (Sesotho), Imbuya (isiZulu) and Vowa (Tshivenda) [10, 34]. It is not known or well documented as to when exactly the vegetable was introduced in South Africa. However, its indigenization became notable around the 1970 s to late 80 s as it gained momentum in usage. Unfortunately, around the $20^{\text {th }}$ century, a declining consumption and utilization trend started to be noticed due to nutrition transition and urban migration. The utilization of this vegetable is reported to be among elderly women. Youth has limited interest in consuming the vegetable due to the stigma of being perceived as food for the poor or being backward food [35]. Recent studies report and classify it as one of the underutilized traditional leafy vegetable (TLV) in the region [12].

The nutritional value of Amaranthus has been studied broadly and all the research studies done yielded similar results [12]. Amaranthus species are an excellent source of protein, having high levels of vitamins such as $\beta$ carotene, vitamin $C$, vitamin $B 2$, folate and rich in dietary minerals such as copper $(\mathrm{Cu})$, zinc $(\mathrm{Zn})$, manganese $(\mathrm{Mn})$, and potassium $(\mathrm{K})$ $[11,12,36]$. Amaranthus leaves offer health benefits for those with hypertension and cardiovascular disease. Regular consumption reduces blood pressure and cholesterol levels while improving the antioxidant status and some immune parameters. The amino acids profile present in Amaranthus helps in easy digestion while the protein content helps in reducing the insulin level in the bloodstream, and therefore contributing to 


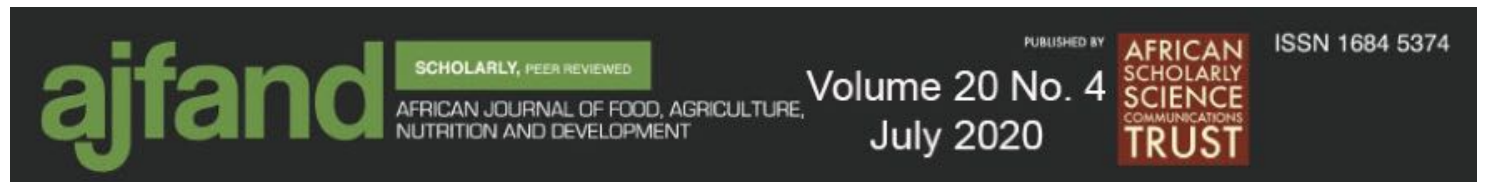

weight loss. The high levels of calcium present in the leaves help in reducing the risk of osteoporosis and other calcium-related issues [37]. Despite the excellent nutritional value of this vegetable, consumer perceptions tend to hinder the appreciation of active consumption of the vegetable as food for humans.

\section{Utilization of Amaranthus leaves}

Previously, the green leaves of Amaranthus have received less attention with regards to research as compared to the grain Amaranthus as well as other green leafy vegetables. In most countries, like Uganda and in Asia, the grain part of Amaranthus is the most commonly consumed and used for home and commercialization purposes. The grains are used as a source of lipids and ingredient for the production of flour, popped seeds, flakes and bread varieties [38]. The ground grain can be used in the production of bread, noodles, cereals, pancakes, cookies, granola, and other starch-based products $[10,12]$. The smaller grains of Amaranthus have an ability to take on a porridge-like texture during cooking, which makes it a reasonable alternative for breakfast [37]. The seeds can be ground and milled into flour, which can be used in mixtures with wheat and maize [39]. They can also, instead of being milled into flour, be used as is in the improvement of the nutritional value of bread.

In sub-Saharan Africa, the green leaves are the most used for household consumption. As a result, recent research results have shown that TLVs are as good or much more nutritious in contributing micronutrients and bioactive compounds to diets as other vegetables [12, 40, 41]. Compared to spinach varieties that are popular and highly consumed, Amaranthus contains three times more vitamin $\mathrm{C}$, calcium and niacin. Compared to lettuce, Amaranthus contains 18 times more vitamin A, 13 times more vitamin C, 20 times more calcium and seven times more iron [32]. The leaves can be eaten raw, cooked as a spinach, as an ingredient in sauces, soups, mixed with other vegetables, eaten as part of the main dish as well as alone [10] or be the main ingredients in other forms of foods or snacks $[10,14]$.

\section{Consumer acceptability of Amaranthus-fortified foods}

Consumer acceptability of Amaranthus and Amaranthus-based food products has been done with the youth. Reports indicate a declining preference and acceptability. For example, a study conducted by Beswa et al. [11] found that with an increased addition of Amaranthus leaf powder to biofortified maize snacks, the acceptability declined. It was also reported that the reduced preference of Amaranthus and Amaranthus-based foods is associated with the lack of knowledge on the nutritional value as well as nutritional benefits of the plant [32]. Nyembe [42] found that the acceptability of processed African leafy vegetables remained the same in comparison to fresh vegetables. The opposite was found for grain Amaranthus-based foods. They were highly accepted in Uganda when they were incorporated into familiar foods. It was concluded that including Amaranthus grains into foods that are familiar would address the issues of malnutrition in that country [43]. In another study, also done in Uganda, which aimed to look at the acceptability of vegetable-enriched foods, it was found that Amaranthus leaves were more acceptable in the production of soups compared to sweet potatoes, which were favored for snacks and porridge [44]. It is important that the product being fortified keeps the physical properties such as appearance, color, cooking qualities and 


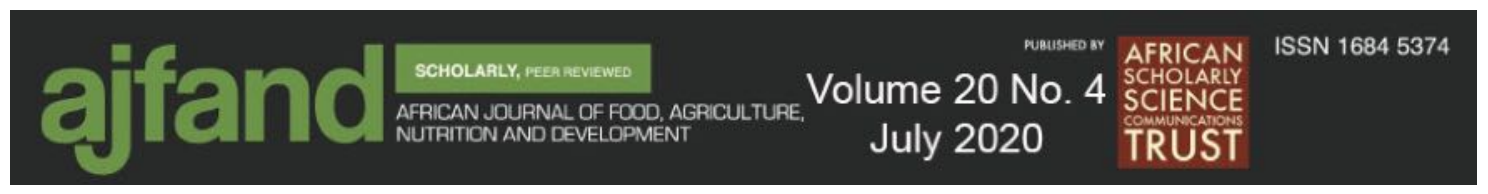

overall sensory acceptability when compared to noodles currently available commercially [2]. The color of flour can be affected by several factors such as flour composition components like ash, protein, starch and phytochemical pigments [45].

\section{CONCLUSION}

This review was done to determine the potential of instant noodles to be fortified with Amaranthus leaf powder. It was found that instant noodle nutritional value can be improved by fortification. It is important, however, to note that the projected output may not be as acceptable to the youth. This is due to the unfamiliar color, which is associated with Amaranthus leaves [11]. In addition, Amaranthus is still perceived as food for poor and backward people, which also contributes to low acceptability of the vegetable to the youth. There is a need, therefore, for the promotion the use of these leaves as healthy food as well as food that can potentially help eradicate hunger and malnutrition. Instant noodles are a convenience food, particularly to students. Therefore, improvement of their nutritional value could provide health benefits to this population. This will eliminate susceptibility to malnutrition as well as other related diseases. Product development around Amaranthus-fortified noodles is recommended. This should be done to test for the effectiveness of Amaranthus leaf powder (ALP) addition on the overall nutritional quality of noodles. Additionally, consumer acceptability evaluation of Amaranthusfortified noodles among students should be done to check if addition of ALP will affect the color, taste and texture of noodles. Incorporating ALP into well-known and acceptable products can lead to acceptance of traditional leafy vegetables and introduce the vegetables back into the mainstream food system. Future studies should explore behavioral interventions to promote consumption among the youth.

\section{ETHICAL APPROVAL}

Ethical approval was not required for this study. 


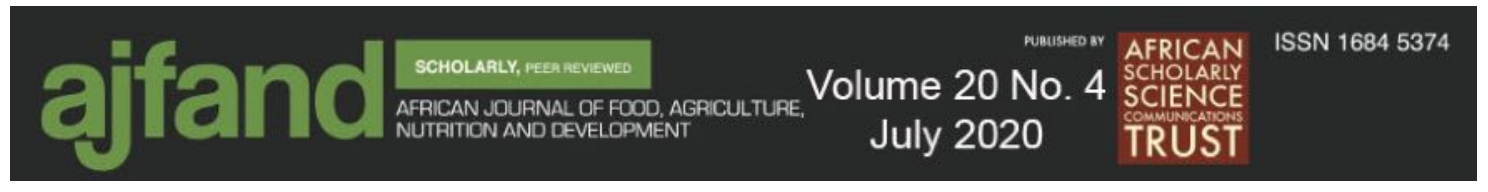

Table 1: Nutritional composition of different types of noodles [4]

\begin{tabular}{|l|l|l|l|l|l|l|l|}
\hline $\begin{array}{l}\text { Type of instant } \\
\text { noodle }\end{array}$ & $\begin{array}{l}\text { Calories } \\
\text { (kcal) }\end{array}$ & $\begin{array}{l}\text { Total } \\
\text { fat } \\
\text { (mg) }\end{array}$ & $\begin{array}{l}\text { Sodium } \\
\text { (mg) }\end{array}$ & $\begin{array}{l}\text { Total } \\
\text { carbs } \\
\text { (g) }\end{array}$ & $\begin{array}{l}\text { Dietary } \\
\text { fiber } \\
\text { (g) }\end{array}$ & $\begin{array}{l}\text { Sugars } \\
\text { (g) }\end{array}$ & $\begin{array}{l}\text { Protein } \\
\text { (g) }\end{array}$ \\
\hline Ramen & 420 & 20 & 0 & 60 & 0 & 0 & 10 \\
\hline Rice & 160 & 0 & 25 & 37 & 0 & 0 & 3 \\
\hline Soba/buckwheat & 226.7 & 1.3 & 600 & 46.7 & 2.7 & 1.3 & 6.7 \\
\hline Bean thread & 260 & 0 & 6 & 65 & 2 & 0 & 0 \\
\hline Wheat flour & 250 & 2 & 192 & 51 & 2 & 1 & 8 \\
\hline Shirataki & 10 & 0 & 0 & 0 & 5 & 0 & 0 \\
\hline Egg & 334 & 2 & 7 & 75 & 1 & 0 & 11 \\
\hline
\end{tabular}




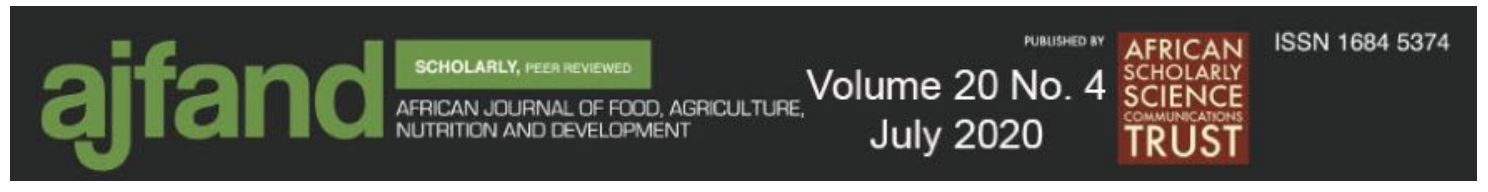

\section{REFERENCES}

1. World Instant Noodles Association (WINA). Global Demand for Instant Noodles. 2019. https://instantnoodles.org/en/noodles/market.html. Accessed on 5 May 2020.

2. Phakare KN, Dagadkhair AC and IS Udachan Enhancement of nutritional and functional characteristics of noodles by fortification with protein and fibre: A review. J Pharmacogn Phytochem. 2018; 7(1):351-357.

3. Adegunwa MO, Bakare HA and OF Akinola Enrichment of noodles with soy flour and carrot powder. Niger Food J. 2012; 30(1):74-81.

4. Sikander M, Malik A, Khan MSG and RG Qurratulain khan, Instant noodles: Are they really good for health? A review. eJBio. 2017; 13(3):222-227.

5. Zahrul-lail NS Influence of instant food among students. Research Hub. 2017; 3(2):1-11.

6. Cotti $\mathbf{C}$ and $\mathbf{N}$ Tefft Fast food prices, obesity, and the minimum wage. Econ Hum Biol. 2013; 11(2):134-147.

7. Zuniga YL, Rebello SA, Oi PL, Zheng H, Lee J, Tai ES and RM Van Dam Rice and noodle consumption is associated with insulin resistance and hyperglycaemia in an Asian population. Br J Nutr. 2014; 111(6):1118-1128.

8. Huh IS, Kim H, Jo HK, Lim CS, Kim JS, Kim SJ, Kwon O, Oh B and N Chang Instant noodle consumption is associated with cardiometabolic risk factors among college students in Seoul. Nutr Res Pract. 2017; 11(3):232-239.

9. Gulia N, Dhaka V and BS Khatkar Instant Noodles: Processing, Quality, and Nutritional Aspects. Crit Rev Food Sci Nutr. 2014; 54(10):1386-1399.

10. Department of Agriculture, Forestry and Fisheries (DAFF). Amaranthus: Production guideline. 2010.

https://www.nda.agric.za/docs/Brochures/Amaranthus.pdf. Accessed on 5 May 2020.

11. Beswa D, Dlamini NR, Siwela M, Amonsou EO and U Kolanisi Effect of Amaranth addition on the nutritional composition and consumer acceptability of extruded provitamin A-biofortified maize snacks. Food Sci Technol. 2016; 36(1):30-39.

12. Alegbejo JO Nutritional value and utilization of amaranth (Amaranthus spp.) A review. BAJOPAS. 2013; 6(1):136-143. 


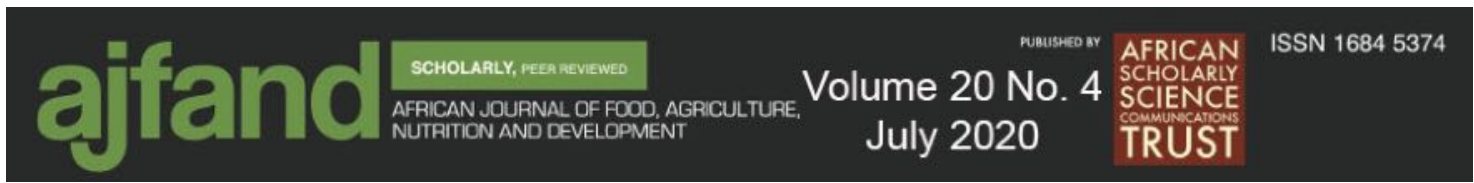

13. Odunlade T, Famuwagun A, Taiwo K, Gbadamosi S, Oyedele D and $\mathbf{O}$ Adebooye Chemical composition and quality characteristics of wheat bread supplemented with leafy vegetable powders. J Food Qual. 2017; Article ID 9536716.

14. Xaba $\mathbf{P}$ and $\mathbf{P}$ Croeser Pigweed: Gardening with traditional useful indigenous plants. Veld \& Flora. 2010; 96(4):184-185.

15. Cardenas-Hernandez AC, Trust B, Loarca-Pina G, Castano-Tostado E, NietoBarrera JO and S Mendoza Improved functional properties of pasta: Enrichment with amaranth seed flour and dried amaranth leaves. J Cereal Sci. 2016; 72(1):8490.

16. Ringier Food. Fortifying with morogo: The green leafy vegetable makes its way to a leading brand of instant noodles. 2015.

http://www.industrysourcing.com/article/fortifying-morogo. Accessed on 2 May 2020.

17. Tan PL, Hanif $\mathbf{M}$ and $\mathbf{F}$ Amalina An exploration of the factors influencing the intention of University students towards the consumption of instant noodles. $J$. Adv. Res Design. 2016; 20(1):1-77.

18. Shin HJ, Cho E, Lee HJ, Fung TT, Rimm E, Rosner B, Manson JE, Wheelan $\mathbf{K}$ and FB Hu Instant noodle intake and dietary patterns are associated with distinct cardio metabolic risk factors in Korea. The Journal of Nutrition. 2014; 144(8): 1247-1255.

19. Sebelin DM World Pasta Day 2013: Pasta, a healthy and sustainable food. 2013. http://www.professionalpasta.it/world-pasta-day-2013-pasta-healthy-sustainablefood/ Accessed on 5 May 2020.

20. Burchi F, Fanzo J and E Frison The role of food and nutrition systems approach in tackling hidden hunger: A review. Int J Environ Res Public Health. 2011; 8(2):358-373.

21. Department of Health. Government Notice: Foodstuffs, cosmetics and disinfectants (Act 54 of 1972): Regulations relating to the reduction of sodium in certain foodstuffs and related matters. 2013. http://extwprlegs1.fao.org/docs/pdf/saf122848.pdf Accessed on 5 May 2020.

22. World Health Organization (WHO). Global Action Plan for the Prevention and Control of NCDs 2013-2020. 2014.

https://www.who.int/nmh/events/ncd_action_plan/en/ Accessed on 5 May 2020.

23. Bird S What's bad about ramen noodles: Food revolution network. 2014. https://foodrevolution.org/blog/ramen-noodles/ Accessed 5 May 2020. 


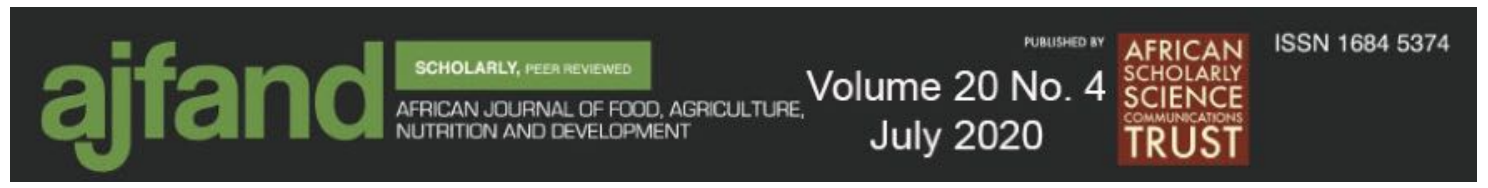

24. Fukutomi S Rāmen connoisseurs: Class, gender, and the internet. In Rath EC and S Assmann (Eds.), Japanese Foodways, Past and Present. Urbana: University of Illinois Press, 2010.

25. Barkley JS, Wheeler KS and H Pachon Anaemia prevalence may be reduced among countries that fortify flour. Br J Nutr. 2015; 114(2):265-273.

26. Barcelon EG, MChua JN, Montemayor JE, Nagalingam MG, Ocampo AE and RM Ong Vegetable added pasta noodles: Physio-chemical composition and consumer acceptability. Int J Agric Innov Res. 2015; 3(6):1570-1574.

27. Ebru E and $\mathbf{H}$ Mehmet The effect of apricot kernel flour incorporation on the physicochemical and sensory properties of noodles. Afr. J. Biotechnol. 2009; 8(1):85-90.

28. Shao S, Duncan AM, Yang R, Marcone MF, Rajcan I and R Tsao Tracking isoflavones: from soybean flour, soy protein isolates to functional soy bread. $J$ Funct Foods. 2009; 1(1):119-127.

29. Ganga MU, Karthiayani A and D Baskaran Study on development of fiberenriched noodles using moringa leaves (Moringa olifera). Asian J Dairy Food Res. 2019; 38(2):145-149.

30. Shere P, Devkatte A and V Pawar Studies on production of functional noodles with incorporation of Spinach puree. Int J Curr Microbiol Appl Sci. 2018; 7(6):1618-1628.

31. Ramu L, Basha SL and V Baskher Physio-chemical analysis of spinach paste fortified instant noodles. Int J Chem Stud. 2018; 6(5):2373-2389.

32. Mnkeni A, Masika $\mathbf{P}$ and $\mathbf{M}$ Maphaha Nutritional quality of vegetable and seed from different accessions of Amaranthus in South Africa. Water SA. 2007; 33(3):377-380.

33. Sanz-Pennella JM, Wronkowska M, Soral-Smitena $M$ and M Heros Effect of whole amaranth flour on bread properties and nutritional value. LWT-Food Sci Technol. 2013; 50(2):679-685.

34. Simoloka A and R Bhikha Benefits of Amaranth plant. 2016. https://tibb.co.za/articles/benefits-of-the-Amaranth-plant.pdf. Accessed on 5 May 2020.

35. Ramdwar MN, Chadee, ST and VA Stoute Estimating the potential consumption level of amaranth for food security initiatives in Trinidad, West Indies. Cogent Food Agric. 2017; 3(1):1321475. 


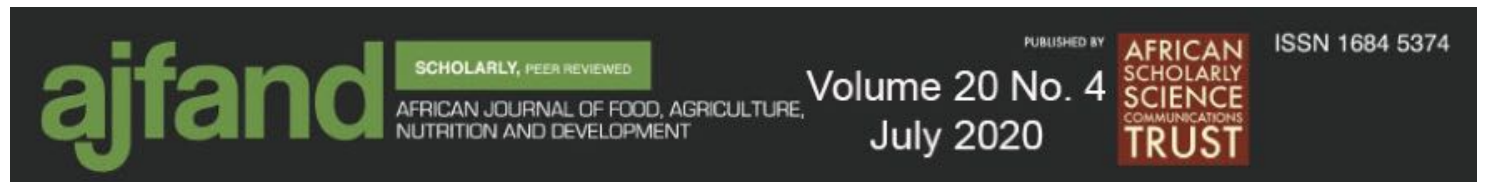

36. Mampholo MB, Sivakumar D and JV Rensburg Variation in bioactive compounds and quality parameters in different modified atmosphere packaging during postharvest storage of traditional leafy vegetables (Amaranthus cruentus $\mathrm{L}$ and Solanum retroflexum). J Food Qual. 2015; 38(1):1-12.

37. Wong K Amaranth grain and greens for health benefits. Nutr Food Sci Int J. 2017; 2(1):13-15.

38. Januszewska-Jozwiak $\mathbf{K}$ and J Synowiecki Characteristics and suitability of amaranth components in food biotechnology. Biotechnol. 2008; 3(1):89-102.

39. Alvarez-Jubete L, Arendt $\mathbf{E}$ and $\mathbf{E}$ Gallagher Nutritive value of pseudocereals and their increasing use as functional gluten-free ingredients. Trends Food Sci Technol. 2010; 21(2):106-113.

40. Maseko I, Mabhaudhi T, Tesfay S, Araya HT, Fezzehazion M and CPD Plooy African leafy vegetables: A review of status, production and utilization in South Africa. Sustainability. 2017; 10(1):16.

41. Smith IF and P Eyzaguirre African leafy vegetables: Their role in the World Health Organization's global fruit and vegetables initiative. Plant Food. 2007; 7(1):3-7.

42. Nyembe SN Preserving traditional leafy vegetables using indigenous knowledgebased drying technologies to improve household food security in Limpopo province, South Africa. PhD. Thesis, University of KwaZulu-Natal, South Africa. 2015.

43. Tibagonzeka J, Wambete J, Muyinda AM, Nakimbugwe D and JH Muyonga Acceptability and nutritional contribution of grain amaranth recipes in Uganda. Afr J Food Agric Nutr Dev. 2014; 14(3):8979-8997.

44. Onwuamaeze NP, Hedwig A and N Dorothy Acceptability, nutritional quality and contribution of vegetable-enriched products to nutrient and energy requirements of school children aged 5 to 13 years. Food Nutr Sci. 2017; 8(02):242-266.

45. Hruškova M, Švec I and H Sekerova Colour analysis and discrimination of laboratory prepared pasta by means of spectroscopic methods. Czech J Food Sci. 2011; 29:346-353. 